\title{
Attribution of ozone changes to dynamical and chemical processes in CCMs and CTMs
}

\author{
H. Garny ${ }^{1}$, V. Grewe ${ }^{1}$, M. Dameris ${ }^{1}$, G. E. Bodeker ${ }^{2}$, and A. Stenke ${ }^{3}$ \\ ${ }^{1}$ Deutsches Zentrum für Luft- und Raumfahrt, Institut für Physik der Atmosphäre, Oberpfaffenhofen, Germany \\ ${ }^{2}$ Bodeker Scientific, Alexandra, New Zealand \\ ${ }^{3}$ Institute for Atmospheric and Climate Science, ETH Zurich, 8092 Zurich, Switzerland
}

Received: 10 December 2010 - Published in Geosci. Model Dev. Discuss.: 8 January 2011

Revised: 25 March 2011 - Accepted: 28 March 2011 - Published: 7 April 2011

\begin{abstract}
Chemistry-climate models (CCMs) are commonly used to simulate the past and future development of Earth's ozone layer. The fully coupled chemistry schemes calculate the chemical production and destruction of ozone interactively and ozone is transported by the simulated atmospheric flow. Due to the complexity of the processes acting on ozone it is not straightforward to disentangle the influence of individual processes on the temporal development of ozone concentrations. A method is introduced here that quantifies the influence of chemistry and transport on ozone concentration changes and that is easily implemented in CCMs and chemistry-transport models (CTMs). In this method, ozone tendencies (i.e. the time rate of change of ozone) are partitioned into a contribution from ozone production and destruction (chemistry) and a contribution from transport of ozone (dynamics). The influence of transport on ozone in a specific region is further divided into export of ozone out of that region and import of ozone from elsewhere into that region. For this purpose, a diagnostic is used that disaggregates the ozone mixing ratio field into 9 separate fields according to in which of 9 predefined regions of the atmosphere the ozone originated. With this diagnostic the ozone mass fluxes between these regions are obtained. Furthermore, this method is used here to attribute long-term changes in ozone to chemistry and transport. The relative change in ozone from one period to another that is due to changes in production or destruction rates, or due to changes in import or export of ozone, are quantified. As such, the diagnostics introduced here can be used to attribute changes in ozone on monthly, interannual and long-term time-scales to the responsible mechanisms. Results from a CCM simulation are shown here as examples, with the main focus of the paper being on introducing the method.
\end{abstract}

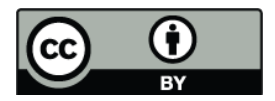

Correspondence to: H. Garny (hella.garny@dlr.de)

\section{Introduction}

The atmospheric ozone layer has been depleted by anthropogenic emissions of CFCs, halons, and other halogen containing compounds over the last decades. The Montreal Protocol and its amendments and adjustments has led to significant reductions in emissions of ozone depleting substances (ODSs) and halogen levels are now decreasing (WMO, 2010). Chemistry-climate models (CCMs) project a return of ozone to 1980 levels in the 21st century (Austin et al., 2010). In addition to ODSs, well-mixed greenhouse gas (GHG) concentrations will also impact the ozone layer, and affect the timing of the return of ozone to $1980 \mathrm{val}-$ ues (Eyring et al., 2010). It is known that enhanced GHG concentrations cool the stratosphere (WMO, 2007). This influences chemical reactions as most ozone destruction reaction rates are temperature dependent (e.g. Portmann and Solomon, 2007). Furthermore, changes in dynamics might alter transport and hence influence the distribution of ozone. In the upper stratosphere, where ozone is largely chemically controlled, the chemical effects are expected to dominate ozone changes while in the lower stratosphere where the lifetime of ozone is long, transport changes are expected to also play a role. The major challenge in determining the importance of chemical versus transport effects on ozone is to untangle their relative influence. Many studies have analysed future ozone projections and inferred the role of different drivers of ozone changes from, for example, the comparison of simulations with and without changes in well-mixed GHGs (Eyring et al., 2010) or from results of linear regression modelling (Oman et al., 2010). In this study, a method is introduced that quantifies ozone transport and allows the effect of transport changes on ozone to be quantified explicitly.

This method consists of three different diagnostics that build on each other. The first is the ozone origin diagnostic developed by Grewe (2006). This diagnostic,

Published by Copernicus Publications on behalf of the European Geosciences Union. 
and modifications made for this study compared to Grewe (2006), together with selected results are shown in Sect. 2. In Grewe (2006), the ozone origin diagnostic was used to study the composition of a climatological mean ozone distribution (in a steady state simulation), while here it is incorporated into a transient simulation.

In the second diagnostic (Sect. 3), changes in ozone from one timestep to the next are reconstructed using the ozone budget equation, thereby attributing these changes to the different source and sink terms of the ozone budget. The tendencies are decomposed into contributions from chemistry and transport. The chemistry contribution is further divided into production and destruction of ozone, which can then also be divided further to study the relative importance of different chemical reaction cycles. The novel aspect of the method developed here is the separation of the transport tendencies into export of ozone and import of ozone out of and into different regions of the atmosphere. This is made possible by incorporating the ozone origin diagnostic and decomposing the ozone tendencies of the additional ozone fields obtained by this diagnostic. The origin diagnostic, in combination with the decomposition of ozone tendencies, is used to calculate the ozone budgets and ozone mass fluxes between different regions. This decomposition can be used to study and understand the local and non-local contributions to the annual cycle and interannual variability in ozone.

The third and final diagnostic allows the attribution of differences in ozone between two climate states (e.g. between two different periods) to changes in the sink and source terms, as shown in Sect. 4. In particular, the relative difference in the mean ozone mixing ratios in a region can be divided into those caused by changes in production rates, destruction rates and transport to or from different regions. This is obtained by using the decomposition of ozone tendencies as performed in the second part of the diagnostic, and expressing the differences in ozone between two periods in terms of changes in the sink and source terms.

A simulation with the chemistry climate model E39C-A (Stenke et al., 2009) is used to demonstrate the method. The simulation is identical to the SCN-B2d simulation described in Garny et al. (2009), and a brief description of the model and the simulation is given in Appendix A. The demonstration of the method is largely independent of the details of the model. The method described in this paper can be applied to any model which supplies the amounts of chemical production and destruction of ozone, i.e. CCMs as well as CTMs, after incorporating the ozone origin diagnostic. A speciality of the model used here is the fully Lagrangian advection scheme ATTILA that provides a large set of trajectories that are used to calculate air mass fluxes. This adds the possibility to compare ozone mass fluxes to air mass fluxes, but the trajectory data are not necessary for the calculation of ozone mass fluxes and the ozone attribution method.

\section{Ozone origin diagnostic}

\subsection{Method}

The ozone origin diagnostic allows partitioning of ozone at any point in the atmosphere into the amount of ozone that originates from each of a certain number of predefined regions dividing the whole atmosphere. A full description of this method is given in Grewe (2006). Technically, in addition to the standard ozone field, a supplementary ozone field for each of the predefined regions is introduced. Here, the atmosphere is divided into nine regions, resulting in nine additional ozone fields. Each of these nine global ozone fields consists of ozone that is produced in one of the nine predefined regions only, i.e. the $i$ th ozone field is global in extent but contains only ozone molecules that were created in region $i$. On the other hand, at each point in the atmosphere, the local destruction rate is applied to all nine ozone fields. Thus, the ozone molecules produced in region $i$, are advected throughout the atmosphere making ozone field $i$, and are eventually destroyed at some point in the atmosphere. The change in ozone mixing ratio for ozone field $i$ over one time step (i.e. the tendency in ozone $\mathrm{O}_{3}^{i}$ ) at a model gridpoint (with longitude $\theta$, latitude $\phi$, altitude $z$ ) that is situated in region $j$ can be expressed as:

$\frac{\partial \mathrm{O}_{3}^{i}}{\partial t}=P \delta_{i j}-D \mathrm{O}_{3}^{i}+T_{i}$

Here $\mathrm{O}_{3}^{i}$ is the mixing ratio of the ozone field $i$ at gridpoint $(\theta, \phi, z) . P$ is the total ozone production at this gridpoint per unit time, i.e. in units of ozone mixing ratio per time (e.g. ppbv s ${ }^{-1}$ ). $D$ is the fraction of the ozone destroyed per unit time at that gridpoint (in units of $1 \mathrm{~s}^{-1}$ ). $T_{i}$ is the net amount of ozone from ozone field $i$ transported to or from the respective point in the atmosphere per unit time, i.e. as well in units of ozone change per time (e.g. ppbv s ${ }^{-1}$ ). The delta operator $\delta_{i j}$ equals 1 if $j=i$ and is zero otherwise, i.e. the ozone production is only added to ozone field $\mathrm{O}_{3}^{i}$ if gridpoint $(\theta, \phi, z)$ lies within region $i$.

It can be shown that the sum of all nine ozone fields is equivalent to the full ozone field at all times if this is true for the initial condition in a mathematically exact way. For all other initial conditions, the sum of the ozone fields also converges exponentially to the full ozone field, i.e. the method is convergent. The time of convergence and thus the spinup time depends on the chemical lifetime and the transport timescale, and an appropriate initialization is recommended to guarantee fast spin-up (see Appendix B). In practice, the sum of the tracer fields might, however, differ from the full ozone field due to numerical diffusion that acts differently on the tracer fields as they have different gradients. Therefore, the mass of the sum of the nine partitioned ozone fields is scaled to the mass of the full ozone field after each time step. 


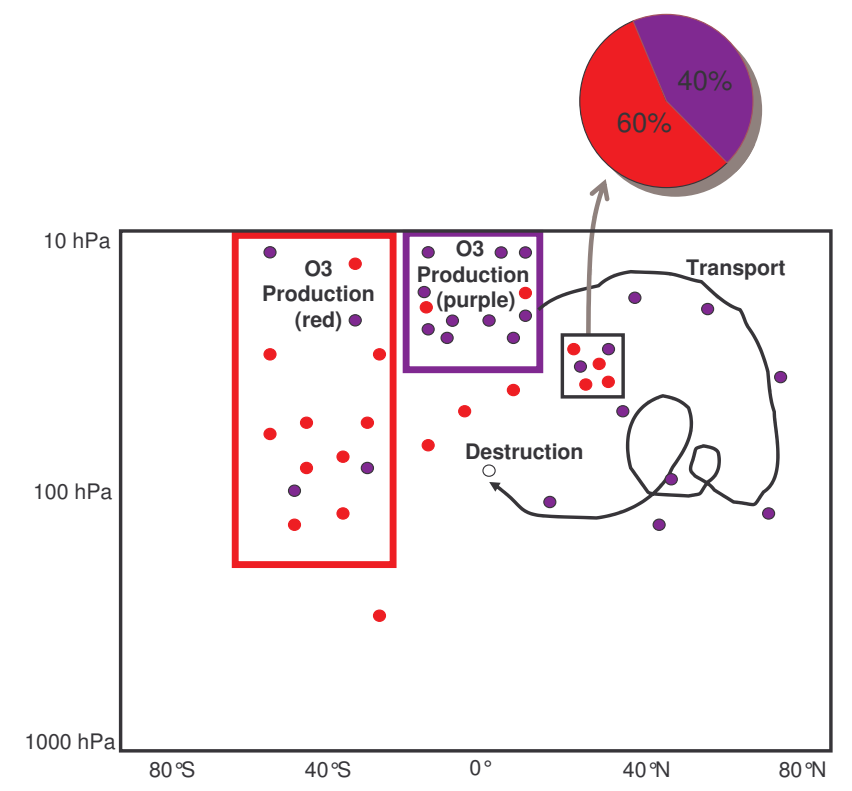

Fig. 1. Schematic illustrating the ozone origin diagnostic. Two source regions are shown (red and purple boxes), in which ozone molecules of the respective colour are produced. The molecules can be transported out of their source region (along some trajectory, illustrated by the black line), and are destroyed eventually. Choosing any subregion of the atmosphere (for example the black box), the contribution of ozone from different source regions to the full ozone field can be determined. For example, in the black box $60 \%$ of the ozone molecules originate from the southern mid-latitude box and $40 \%$ from the tropical stratosphere box.

Hence it is always given that

$\mathrm{O}_{3}(\theta, \phi, z, t)=\sum_{i=1}^{9} \mathrm{O}_{3}^{i}(\theta, \phi, z, t)$

In Grewe (2006) it was shown that the numerical accumulated error in ozone is less than $2 \%$ almost everywhere in the atmosphere; only small regions around the tropical tropopause region and at high latitudes showed errors of more than $5 \%$. Since in the model version used in the current study the semi-Lagrangian advection scheme of the model in Grewe (2006) was replaced by the fully Lagrangian scheme ATTILA, the errors due to numerical diffusion are expected to be even smaller (Stenke et al., 2008).

The ozone origin diagnostic is illustrated schematically in Fig. 1. Ozone from two different source regions is shown. In each source region, ozone molecules of the respective "colour" are produced, i.e. "red" molecules in the midlatitude source region and "purple" molecules in the tropical source region. The created ozone molecules are transported within and out of their source region, and will be destroyed eventually at some point in the atmosphere. The ozone molecules originating from a particular source region (i.e. of a particular "colour") therefore make a global ozone

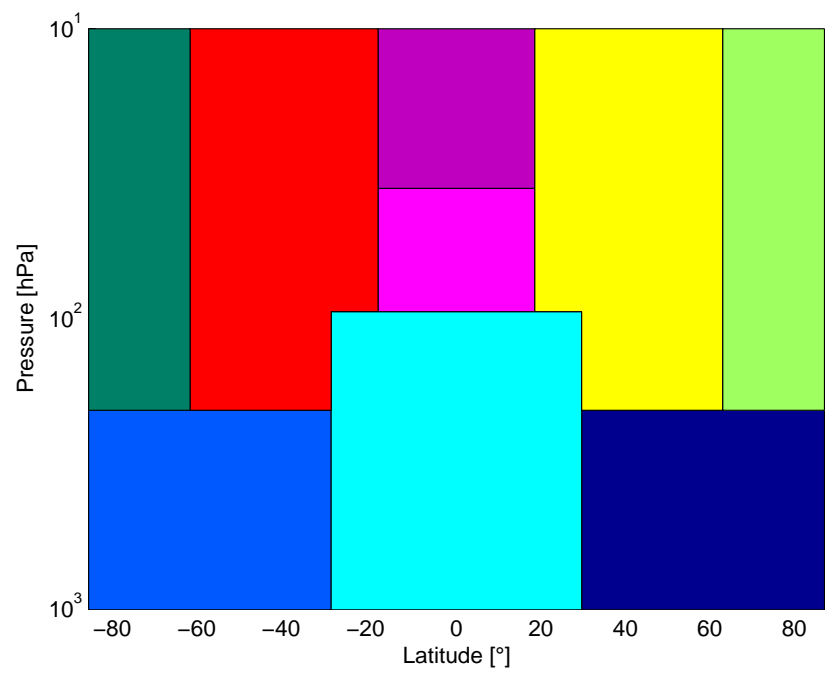

Fig. 2. Defined regions of the ozone origin diagnostic with each region being marked in one colour.

field. At any point in the atmosphere, the method allows ozone to be partitioned into molecules originating from the defined regions, as shown in the example of the black box in Fig. 1 .

The partitioning of the atmosphere into the nine regions of ozone origin is shown in Fig. 2. The regions are chosen so that three boxes represent the troposphere (northern and southern extratropics and tropics) and the six remaining regions represent different parts of the stratosphere. In contrast to Grewe (2006), the extratropical stratosphere is not subdivided into lower and middle stratosphere but into midlatitudes and high latitudes. Grewe (2006) showed that ozone produced in the extratropical lower stratosphere is not a major contributor to the total amount of ozone anywhere in the atmosphere. The objective of the subdivision implemented here is to examine the role of ozone production at high latitudes in summer and to study transport of ozone between high, middle and low latitudes. In general, the subdivision of the atmosphere into any number of regions can be chosen arbitrarily and customized to the subject of interest.

The latitudinal boundaries are chosen to resemble barriers to transport, i.e. the tropical and polar barrier, and to subdivide the atmosphere according to regions of ozone production and destruction. Figure 3 (top) shows the climatological mean net ozone production in the solstice seasons in the 2000s. The boundary between the regions representing the tropics and mid-latitudes is chosen so that in the winter hemisphere the boundary divides the tropical region of net production from the region of net destruction in the winter extratropics. The lower panels of Fig. 3 show the mean residual circulation and the location of the polar vortex. The boundary between the regions representing middle and high latitudes resembles approximately the separation of air masses 

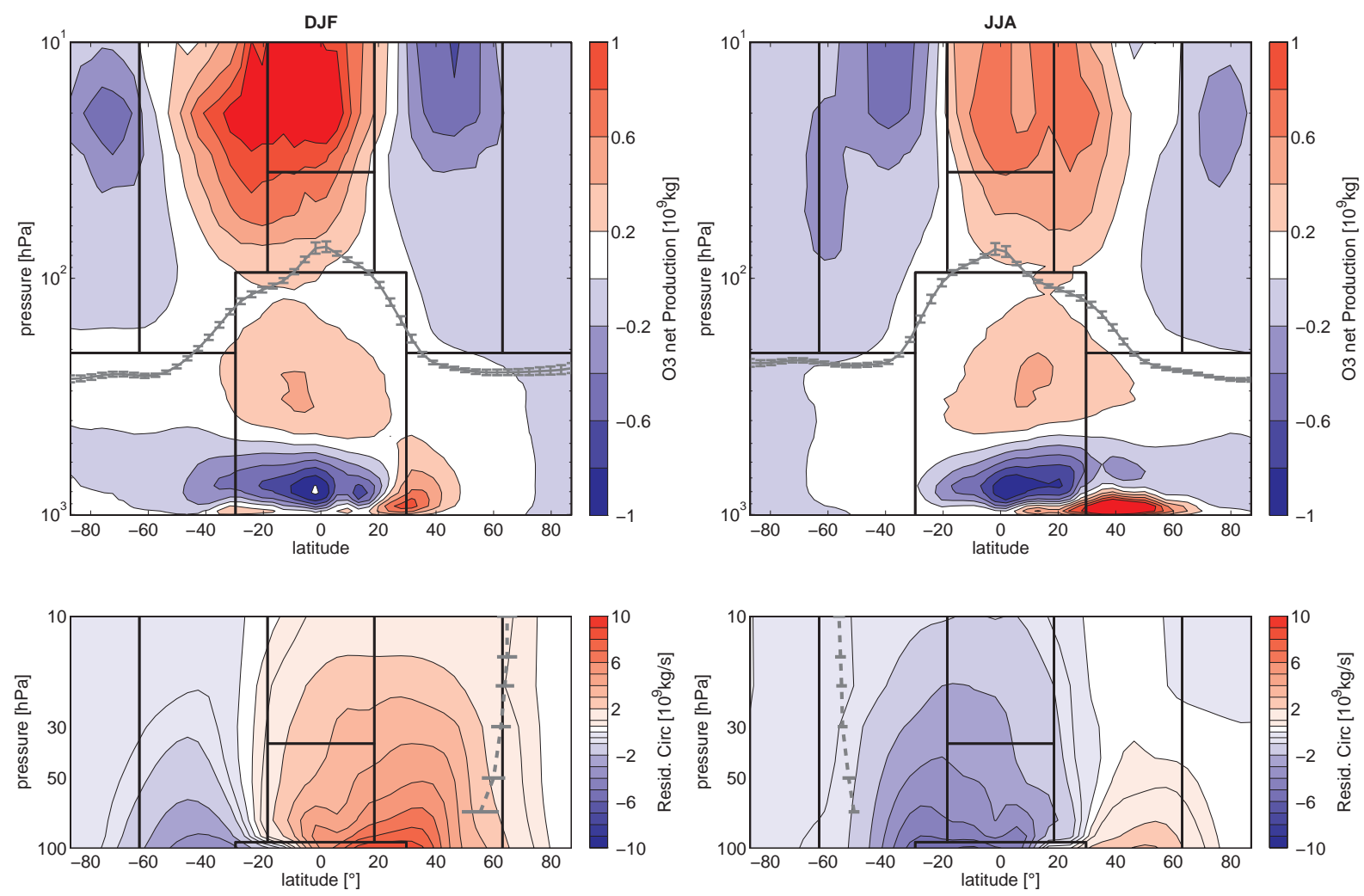

Fig. 3. Top: climatology (2000-2009) of the net ozone production in kg per gridbox and over the three-month period DJF (left) and JJA (right). The grey solid line is the mean position of the dynamical tropopause. Bottom: climatology of the mass-weighted streamfunction of the residual circulation in the stratosphere. The grey dashed line is the location of the winter hemisphere jet (latitude of maximal zonal wind speed). The vertical and horizontal bars denote the inter-annual variability as $1 \sigma$.

inside and outside the polar vortex, which acts as a barrier to transport. The location of the jet (and the transport barrier) varies and, especially in the Northern Hemisphere, the vortex is not zonally symmetric. The location of the wind maxima in the seasonal mean, as shown in Fig. 3, is, however, relatively stable from year to year (as indicated by the horizontal bars that represent one standard deviation) and close to the defined boundaries between middle and high latitudes. The model levels that separate the three tropospheric regions from the stratospheric regions are chosen to roughly represent the tropopause. The structure of the dynamical tropopause (specified as 3.5 PVU, see Grewe and Dameris, 1996) varies for different seasons (see Fig. 3), but the interannual variability in the location of the tropopause is relatively small (as indicated by the $1 \sigma$ vertical bars). The location of the tropopause, the wind jets and the zero-line of net ozone production is almost unchanged in the future (2040-2049) compared to the 2000s (not shown). Therefore, it can be assumed that air masses with similar properties are described by the fixed boxes both in the present and future.

Fixed regional boundaries following model levels and latitudinal grids are used here. This allows an analysis of the properties of ozone from a certain geographical region, but air masses are not separated according to their dynamical origin (i.e. air masses within the polar vortex). Therefore, for example, it is not possible to make conclusions regarding transport across the polar barrier if ozone molecules originating from a polar box are detected in mid-latitudes they might have been equatorward of the polar barrier while in the polar box. The same is true for cross-tropopause transport: as the boundary between the "tropospheric" and "stratospheric" boxes is not coincident with the tropopause, air masses that are transported across this boundary are not necessarily crossing the tropopause. Therefore, by using fixed boundaries, the question can be addressed regarding how much ozone originating from different geographical regions contributes to the ozone amount at a certain point. However, it cannot be concluded explicitly whether ozone crossed dynamical boundaries. To separate air masses according to their dynamical region of origin it would be necessary to use flexible boundaries such as the tropopause or mixing barriers defined by e.g. PV gradients. However, this makes the interpretation more difficult since changes in the ozone mass within a region might either be due to changes in the ozone sources and sinks or due to changes in the size of the region. 


\subsection{Results: ozone origin}

As an illustrative example, an analysis of ozone for the northern mid-latitudes using the ozone origin diagnostic is shown in Fig. 4. The mean ozone mixing ratio averaged over the northern mid-latitudinal source region, i.e. the yellow region in Fig. 2, has an annual cycle (black line) with highest values in northern spring and lowest values in northern autumn. The partitioning of ozone into its regions of origin shows that the annual cycles in ozone from different origins have much larger amplitudes, but partially cancel. The yellow line shows the annual cycle in ozone that originates locally, i.e. if the northern mid-latitude stratosphere would not import ozone from any other region of the atmosphere, this is how the annual cycle in ozone would appear. The locally produced ozone has highest mixing ratios in summer and lowest in winter, as expected. Ozone of tropical origin (purple line), on the other hand, clearly shows a wintertime maximum, being in phase with the maximum in the northern mid-latitude stratospheric ozone. Even though locally produced ozone makes the largest contribution (67\% in the annual mean), the annual cycle is determined primarily by ozone of tropical origin (which only contributes $22 \%$ in the annual mean). Ozone from other regions makes a negligible contribution to ozone mixing ratios in the northern mid-latitudes. The fact that the annual cycle in mid-latitude ozone is induced by transport of tropical ozone into mid-latitudes is commonly known. It is, however, somewhat surprising that tropical ozone makes still only a relatively small contribution to the total amount of ozone compared to what is produced locally. This result agrees with the findings of Grewe (2006).

The relative contribution of each of the nine ozone fields to the net ozone mixing ratio at each point (i.e. the contribution of each "colour" of ozone, following the example of Fig. 1) is shown as a latitude-height map in Fig. 5. Each panel illustrates the contribution of the ozone field from one source region, so that the sum of the nine plots equals to 1 everywhere. It can be seen that in the middle stratosphere, locally produced ozone dominates over transported ozone (as contributions are high within the source regions), which can be expected from strong ozone production and short life-times. In the tropical middle stratosphere, the contribution of local ozone is highest, while in the polar regions only about $30 \%$ of the ozone at the upper levels is of local origin. In the polar lower stratosphere even less ozone is of local origin, and mostly originates from the mid-latitudes. Ozone originating in the tropical stratosphere is transported poleward and downward, apparent by the regions of enhanced contribution in the extratropics. This transport is due to the residual circulation, which transports air from the tropics into the extratropics of the winter hemisphere (see Fig. 3 bottom). In the summer hemisphere, the circulation is more confined in its vertical extent and implies weak transport of air from the mid-latitudes to high latitudes in the lower stratosphere. As the meridional circulation is stronger in the

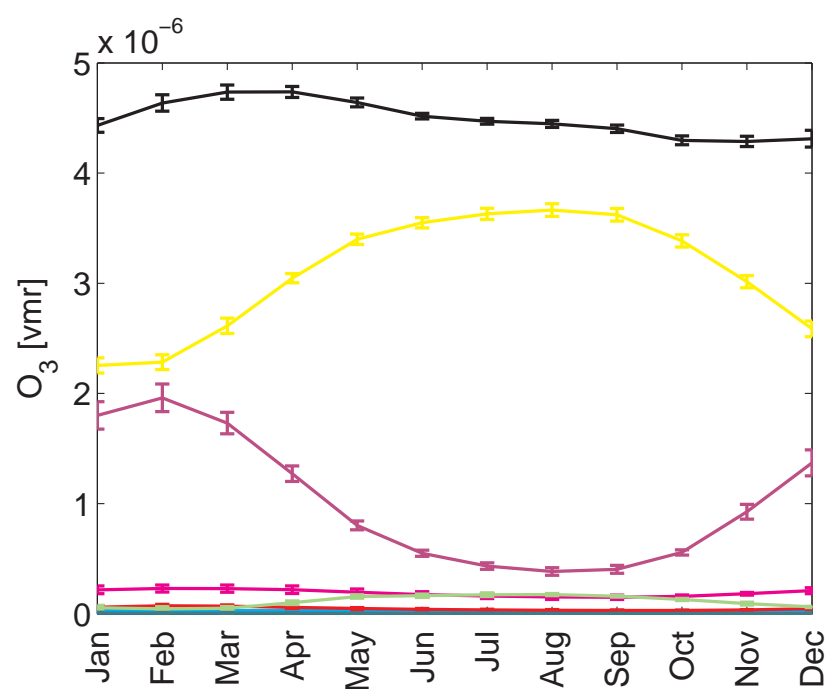

Fig. 4. Climatology (2000-2009) of the annual cycle in ozone mixing ratios averaged over the northern mid-latitude stratosphere (the yellow region in Fig. 2). The black line is the mean ozone mixing ratio and the colours are the mean mixing ratios of the nine ozone origin tracers (colours follow Fig. 2; yellow: local, purple: tropical middle stratosphere, pink: tropical lower stratosphere). The vertical bars denote the $1 \sigma$ variability over the analysed decade.

Northern Hemisphere (see Fig. 3), tropical ozone contributes more there. In the annual mean, the contribution of tropical ozone to mid-latitude ozone is, however, only about 10-20\%, but shows a distinct annual cycle (as shown for tropical ozone in the northern mid-latitudes above). Another interesting feature is the spread of ozone originating in the tropical lower stratosphere to higher latitudes in the lower stratosphere, which approximately follows the structure of isentropic levels in this region. Mid-latitude ozone also shows tongues of $\sim 10 \%$ contribution reaching into lower latitudes. These features are indicative of frequent wave breaking events that mix tropical and extratropical air (e.g. Randel et al., 1993), leading to transport of ozone between low latitudes and extratropics.

These results, as well as the results of Grewe (2006), analyse exclusively the climatological mean origin of ozone. To study the long-term changes in the origin of ozone, different decades from the transient simulation used here are compared in Fig. 6, showing the difference in mean ozone mixing ratios in the northern mid-latitudes between the present (2000s) and the future (2040s). Ozone mixing ratios increase through all seasons, and the annual cycle becomes more pronounced. Examination of the individual ozone fields, consisting of ozone of different origin, shows that during winter, this increase is largely due to enhanced ozone amounts originating in the tropics. This suggests that enhanced transport of ozone from the tropics to mid-latitudes is the cause of increasing ozone mixing ratios in the mid-latitudes. However, 

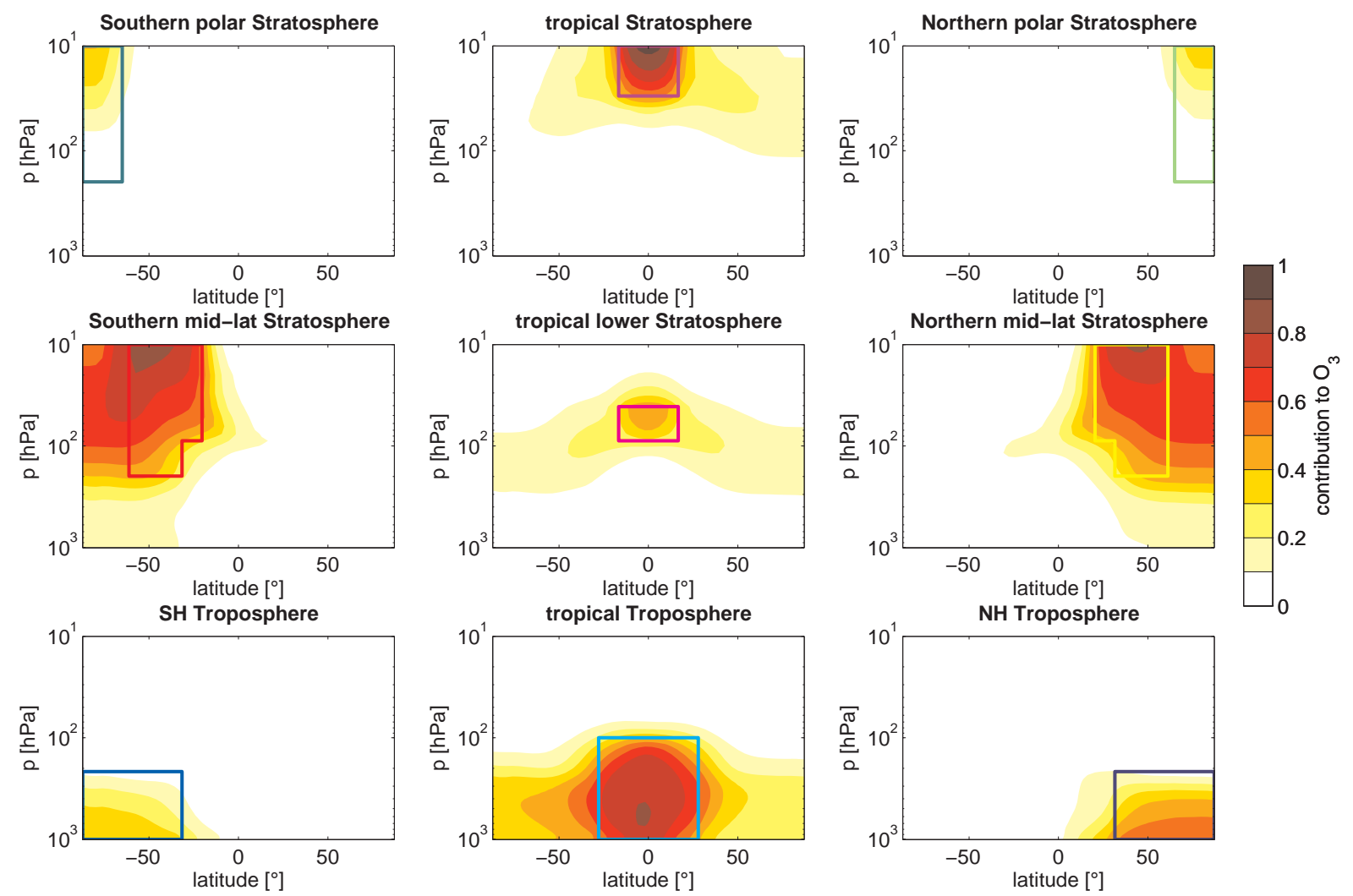

Fig. 5. Climatology (2000-2009) of the contribution of ozone originating from the regions indicated by the boxes to the full ozone field $\left(\mathrm{O}_{3}^{i} / \mathrm{O}_{3}\right)$ for each of the nine source regions.

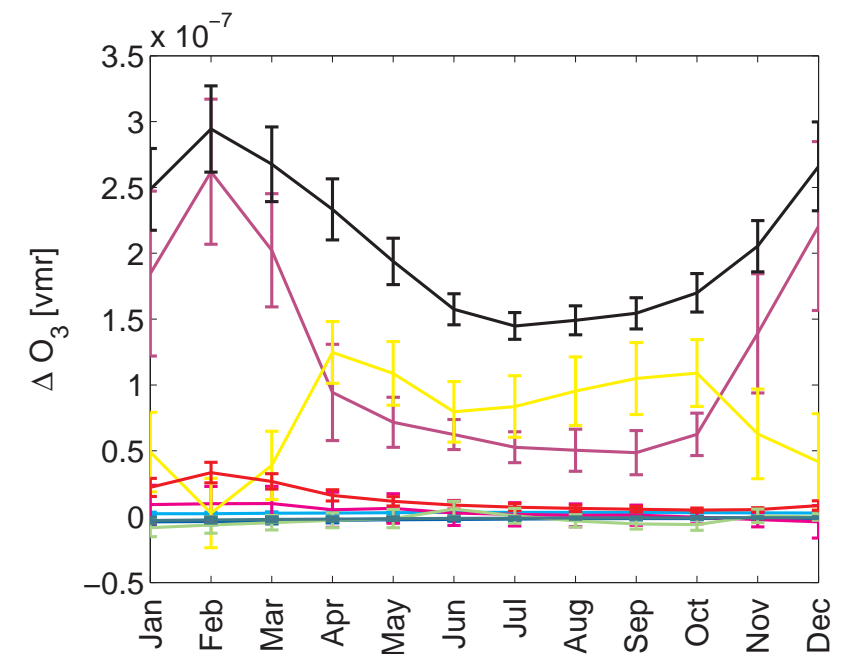

Fig. 6. As in Fig. 4, but difference 2040s minus 2000s. Colours follow Fig. 2: yellow: local, purple: tropical middle stratosphere, pink: tropical lower stratosphere. Here, the vertical bars denote the $1 \sigma$ uncertainty in the differences. care has to be taken in the interpretation of these results: the enhanced mixing ratios of ozone of tropical origin in the midlatitudes could also result from a decrease in the mid-latitude destruction rates. The same problem arises for the enhancement of locally produced ozone: the increase could result from more ozone production, decreased destruction rates, or more export of mid-latitude ozone. This highlights the need to define a method which separates the effects of dynamics (transport) and chemistry (production and destruction) to assign long-term changes in ozone to these processes. In the next section, a method which allows the attribution of changes to transport and chemistry separately is presented.

\section{Transport of ozone masses}

\subsection{Method}

The amount of ozone within some volume in the atmosphere changes due to chemical production and destruction and due to transport of ozone into or out of that region. The time integrated ozone budget (Eq. 1) can be used to estimate the transport tendency of ozone over a certain time interval $d t$ : 
$\left[T_{i}\right]=d \mathrm{O}_{3}^{i}-\left([P] \delta_{i j}-\left[D \mathrm{O}_{3}^{i}\right]\right)$

The operator [.] indicates the integrated quantity over the time step $d t .\left[T_{i}\right]$ is the amount of ozone originating in region $i$ that is transported to (or from) a given point in the atmosphere during $d t$. To obtain $\left[T_{i}\right]$, it is necessary that the production and destruction rates of ozone are known separately, i.e. these fields need to be available as model output. Here, the production and destruction rates are available as means over one time interval. The time interval $d t$ over which the transport is calculated is chosen here as one month. The ozone tendency $d \mathrm{O}_{3}^{i}$ is then the accumulated change in $\mathrm{O}_{3}^{i}$ over the course of a month, which is equal to the difference in $\mathrm{O}_{3}^{i}$ between the first and last timestep of the month. This is illustrated in Fig. 7, where the ozone tendency is marked by the blue vertical arrows. The sum of the production and destruction, respectively, over each time step in a month is the total ozone production and destruction tendency. The monthly tendencies are used to obtain a monthly transport tendency using Eq. (3). In principle, the transport estimate does not depend on the chosen integration time interval.

The availability of the production and destruction tendencies allows an estimate of the total transport tendency $[T]$ for each gridpoint of the atmosphere. This is the net transport, i.e. the sum of ozone transported away from this region and ozone imported from other regions. Incorporating the ozone origin diagnostic allows the export of ozone from a region and the import of ozone originating in the 8 other regions to be distinguished. It is therefore possible to determine the ozone fluxes between all regions.

The production and destruction terms are dominant in Eq. (3), and the transport tendency $\left[T_{i}\right]$ is a small residual and therefore subject to numerical uncertainties. A numerical discrepancy arises from the fact that in the chemistry scheme of the model, the saved diagnostics of production and destruction are calculated directly from the reaction rates and concentrations of the rate limiting reactions, while the ozone budget differential equation is solved using a semi-implicit numerical integration scheme (here: Eulerian backward formulation). This leads to a discrepancy between the saved production and destruction terms and the ozone tendencies. To account for this, the production and destruction values are subsequently adjusted so that the global ozone budget is closed, with the constraint that the adjusted production and destruction terms should be as close as possible to the initial values. As this adjustment is applied only to the output, no accumulation of errors occurs. For the full global ozone field, the adjustments are $\sim 1 \%$. The estimated mass fluxes $\left[T_{i}\right]$ are affected by the adjustment mostly by less than $10 \%$.

\subsection{Results: local ozone budget and mass fluxes}

The results for the northern mid-latitudes are shown here as an example of the decomposition of ozone tendencies

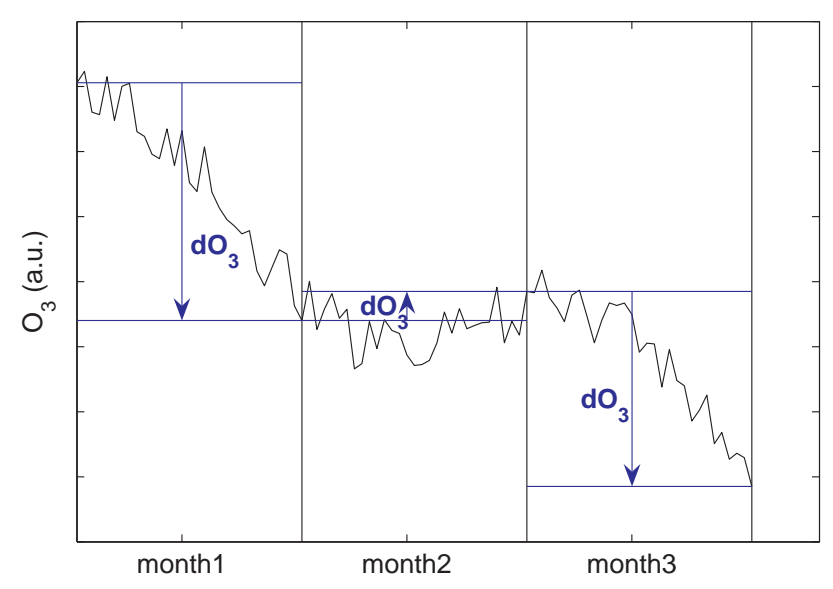

Fig. 7. Schematic illustrating monthly ozone tendencies. An arbitrary ozone time series (with arbitrary units) is shown for three months. The difference between the ozone value at the beginning and the end of the months (blue horizontal lines) is the same as the accumulated change in ozone over the course of each month (blue arrows).

in production, destruction and transport. Figure 8 shows a climatology of the monthly tendencies of the nine ozone fields averaged over the northern mid-latitude region. As the ozone tendencies are the changes within one month, they are equivalent to the time derivative of the annual cycle in ozone shown in Fig. 4. While local ozone accumulates from February to August, it decreases through the other half of the year. Ozone of tropical origin (the contributor to northern mid-latitude ozone second in importance) shows a reversed annual cycle with negative tendencies in the first half of the year and positive tendencies in the second half of the year. The lower panel in Fig. 8 shows the decomposition of the tendencies into the contributions by production (which is different from zero only for locally produced ozone), destruction and transport. Note that the scale of these tendencies is one order of magnitude larger than the net tendencies, i.e. the net change in ozone is a small residual between production, destruction and transport. The terms are shown as defined in Eq. (3), i.e. production and destruction are both positive, and positive transport tendencies indicate import while negative transport tendencies denote export of ozone.

Local ozone in the mid-latitudes is produced largely in summer, when the solar irradiance is strongest. The destruction of local ozone shows a similar annual cycle as the production term, but with a slight lag. The net production is $\sim 20 \%$ of the total production, i.e. production is largely offset by destruction as expected from the relatively short lifetime of ozone in this region. The transport tendency of local ozone is negative throughout the year, as expected, as local ozone can only be exported and not imported. The transport tendencies show a relatively small annual cycle. 

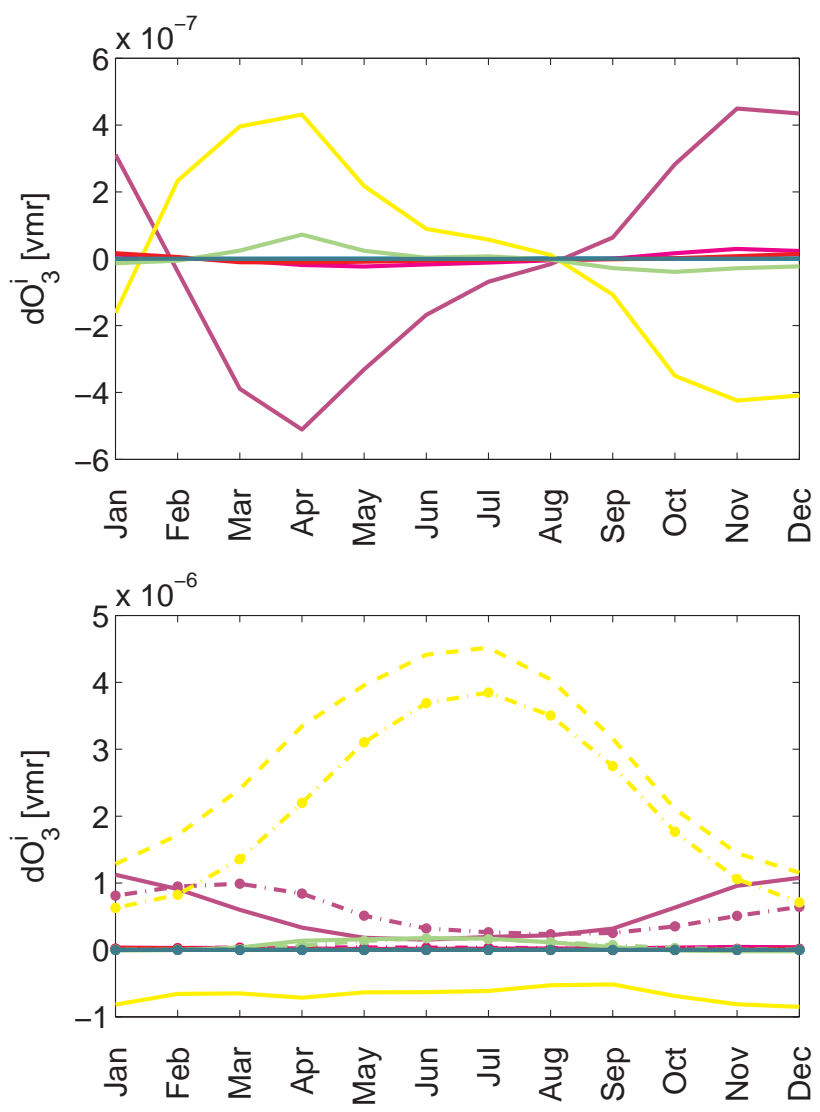

Fig. 8. Climatology (2000-2009) of the annual cycle in the net monthly tendencies $d \mathrm{O}_{3}^{i}$ in ozone (top) and in the lower panel the tendencies due to transport $\left(T_{i}\right)$ (solid line), production $(P)$ (dashed line) and destruction $\left(D_{3}^{i}\right)$ (dash-dotted line) in the northern midlatitudes. Yellow lines are local mid-latitude ozone, purple lines tropical ozone.

Ozone originating in the tropical middle stratosphere makes an important contribution to northern mid-latitude ozone (see purple line in Fig. 8). The transport tendency is close to zero in summer, increases through autumn and into winter, and then decreases in spring. This behaviour is as expected since the transport by the BDC is strongest in northern winter (see Fig. 3). The destruction of ozone of tropical origin in the mid-latitudes follows the transport tendencies, but lags by about 1-2 months. Therefore, the net tendency (sum of transport and destruction) is positive until February, when the amount of ozone transported into the mid-latitudes exceeds the destruction. After February, more ozone of tropical origin is destroyed in the mid-latitudes than resupplied, and the mixing ratio of that ozone decreases.

The incorporation of this diagnostic allows an explanation of the annual cycle in ozone in the mid-latitudes. Ozone of tropical origin peaks in February (see Fig. 4), but this is not because transport is strongest in this month but rather because the balance between transport and destruction is positive until February. The annual cycle in local midlatitude ozone is dominated by the seasonal dependence of ozone production. The sum of locally originating ozone and ozone originating in the tropics determines the annual cycle of ozone in the mid-latitudes: the maximum in mid-latitude ozone in March to April results from a combination of elevated amounts of tropical ozone (that is destroyed and thus decreases strongly afterwards) and increasing production of local ozone (which was low earlier in the year).

This application of the ozone attribution method allows an improved understanding of the spring-time maximum in ozone due to transport accumulation over the winter as follows: transport itself peaks in January, and the accumulation of ozone of tropical origin peaks in February. The maximum in ozone is, however, found in March to April due to the additional effect of local ozone production. If only the transport effect would determine the spring-time maximum it would take place about 1-2 months earlier. This detailed analysis of the causes of the annual cycle in ozone is possible also for the other regions.

The monthly transport tendencies for all regions are illustrated in Fig. 9 (left) as annual mean mass fluxes between the different regions of the atmosphere for the 2000-2009 climatology. Fluxes are shown only between selected regions; a complete list of fluxes between all regions is given in Table 1. Together with the ozone fluxes, the annual mean ozone budget for each region is shown in Fig. 9. The net transport tendency $T$ does not necessarily equal the sum of the arrows pointing to and from a region, as not all fluxes are shown for clarity.

To compare the transport of ozone to transport of air masses, the trajectories from the Lagrangian advection scheme ATTILA are used to calculate air mass fluxes that are shown in the right hand panel of Fig. 9. The trajectories are calculated online and used for the transport of all trace gases, and are saved 12-hourly so that a database of about 500000 trajectories is available at each time step. To calculate the mass fluxes, the atmosphere is then divided into the same regions as in the ozone origin diagnostic. The trajectories that are located in the region of interest at the end of the month are followed backward over the course of the month. As each trajectory represents an equal mass of air, simple counting of trajectories originating from the nine regions gives the total mass flux of air within one month. Due to mass conservation, the sum of the imported and exported mass in each region is zero. This is robustly fulfilled in the model, the sum of export and import is less than $1 \%$ of the total export in all regions except the tropical lower stratosphere, where the error is $2.6 \%$. The cancellation of import and export for air mass fluxes is contrary to ozone fluxes, since ozone has chemical sinks and sources. The air mass fluxes are approximately 6 orders of magnitude larger than the ozone mass fluxes, which is reasonable considering that ozone mixing ratios are on the order of parts per million $\left(10^{-6} \mathrm{~kg} \mathrm{~kg}^{-1}\right)$. 

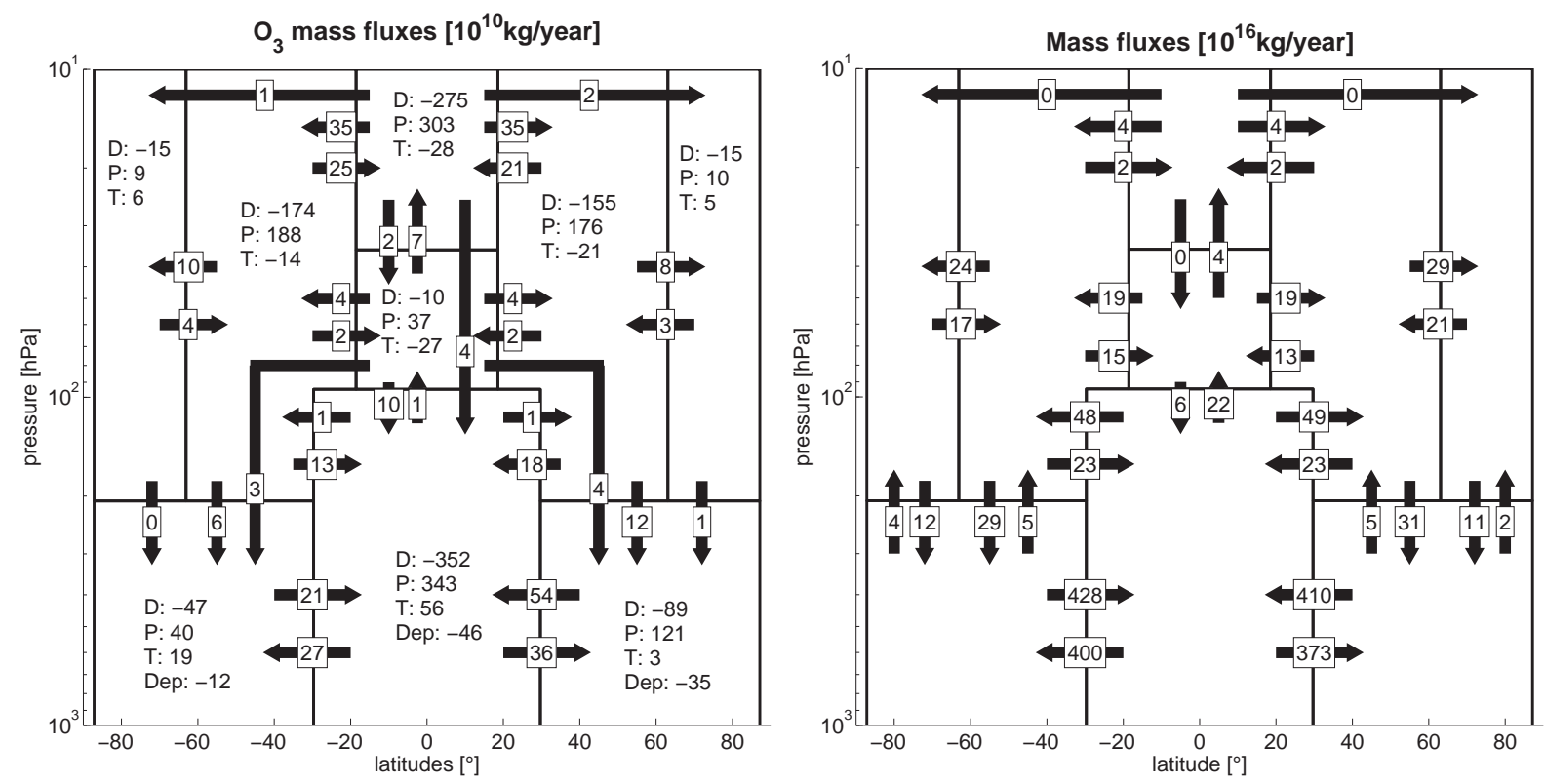

Fig. 9. Climatology (2000-2009) of annual mean ozone mass fluxes $\left(10^{10} \mathrm{~kg} \mathrm{yr}^{-1}\right)$ (left) and air mass fluxes $\left(10^{16} \mathrm{~kg} \mathrm{yr}^{-1}\right)($ right). In the upper figure, the annual mean ozone budget of each region is shown, i.e. the total destruction $(D)$, production $(P)$ and net transport $(T)$. In the troposphere, also the deposition (Dep) is listed separately. Values are rounded, i.e. mass fluxes shown as " 0 " are smaller than $0.5 \times 10^{10} / 0.5 \times 10^{16} \mathrm{~kg} \mathrm{yr}^{-1}$, respectively.

Table 1. Annual ozone mass transport in $10^{10} \mathrm{~kg} \mathrm{yr}^{-1}$ from each predefined region to each of the eight other regions.

\begin{tabular}{|c|c|c|c|c|c|c|c|c|c|c|}
\hline & \multicolumn{9}{|c|}{ TO } \\
\hline & & $\mathrm{nhT}^{1}$ & shT & $\mathrm{tT}$ & tLS & $\mathrm{tS}$ & $\mathrm{nmS}$ & $\mathrm{smS}$ & $\mathrm{npS}$ & $\mathrm{spS}$ \\
\hline \multirow{9}{*}{$\begin{array}{l}\sum_{0} \\
\frac{\alpha}{I}\end{array}$} & nhT & - & 1.42 & 53.73 & 0.02 & 0.09 & 0.09 & 0.05 & 0.01 & 0.00 \\
\hline & $\operatorname{shT}$ & 0.65 & - & 21.38 & 0.00 & 0.07 & 0.01 & 0.02 & 0.00 & 0.01 \\
\hline & $\mathrm{tT}$ & 35.55 & 27.37 & - & 0.56 & 0.48 & 0.93 & 1.06 & 0.12 & 0.17 \\
\hline & tLS & 4.37 & 2.53 & 10.38 & - & 7.49 & 3.87 & 3.88 & 0.54 & 0.49 \\
\hline & $\mathrm{tS}$ & 2.15 & 0.99 & 4.20 & 1.80 & - & 34.54 & 35.40 & 1.97 & 1.00 \\
\hline & $\mathrm{nmS}$ & 12.46 & 1.54 & 17.63 & 2.00 & 20.84 & - & 1.00 & 8.39 & 0.11 \\
\hline & $\mathrm{smS}$ & 1.90 & 6.38 & 13.05 & 2.12 & 24.59 & 1.23 & - & 0.14 & 9.74 \\
\hline & $\mathrm{npS}$ & 1.32 & 0.13 & 1.57 & 0.03 & 0.13 & 2.67 & 0.00 & - & 0.00 \\
\hline & $\mathrm{spS}$ & 0.12 & 0.45 & 0.78 & 0.05 & 0.16 & 0.00 & 3.51 & 0.00 & - \\
\hline
\end{tabular}

$1 \mathrm{nhT}=$ northern extratopical troposphere, $\mathrm{shT}=$ southern extratropical troposphere, $\mathrm{t} T=$ tropical troposphere, tLS $=$ tropical lower stratosphere, $\mathrm{tS}=$ tropical stratosphere, $\mathrm{nmS}=$ northern mid-lat stratosphere, $\mathrm{smS}=$ southern mid-lat stratosphere, $\mathrm{npS}=$ northern polar stratosphere, $\mathrm{spS}=$ southern polar stratosphere

Note that there is a slight difference in the ozone flux and air mass flux calculation concerning the transport timescales. The mass fluxes calculated from the trajectories are the fluxes that leave the source region and enter the destination region within one month. The transport time-scale of the ozone fluxes, on the other hand, cannot be determined from the diagnostic as performed here; it is only known that the ozone mass enters the region of destination within the regarded month (adding to the monthly ozone tendency during this month) and that the ozone molecules originated from the source region at some time before that. However, it might have taken the ozone molecules a longer time than one month to travel from the source to the destination region. In the upper stratosphere, where life-times are typically shorter than one month, it can be assumed that the ozone molecules were transported within a month or less, while in the lower stratosphere, the transport time scales are longer.

Many previous studies have dealt with mass or tracer exchange across the tropopause, but there are few estimates of mass fluxes between different regions of the stratosphere. The results obtained with the method described here, can be compared to the estimates of troposphere-stratosphere 
ozone exchange of previous studies. The tropospheric ozone budget including the contribution of stratospheric ozone to tropospheric ozone has been studied in many models, as summarized by Stevenson et al. (2006). The contribution of stratospheric ozone transport to tropospheric ozone is estimated at $55 \pm 17 \times 10^{10} \mathrm{~kg} \mathrm{yr}^{-1}$ from the multi-model mean in Stevenson et al. (2006), comparing well with estimated cross-tropopause ozone fluxes from observations of 45 to $59 \times 10^{10} \mathrm{~kg} \mathrm{yr}^{-1}$ by Gettelman et al. (1997). In the study presented here, the total net ozone mass flux between the stratospheric and the tropospheric regions is $78 \times 10^{10} \mathrm{~kg} \mathrm{yr}^{-1}$, i.e. substantially larger than these previous estimates. The overestimation of ozone mass fluxes might be either due to an overestimation of the air mass exchange between troposphere and stratosphere or due to the too high gradients in ozone mixing ratios between the troposphere and stratosphere in the model used here. The air mass fluxes between the broadly defined tropospheric and stratospheric boxes presented here (shown in Fig. 9 right) are strongest in mid-latitudes, with values of net downward fluxes of around $25 \times 10^{16} \mathrm{~kg} \mathrm{yr}^{-1}$. These values compare well with observational estimates by Grewe and Dameris (1996), having found strongest cross-tropospause mass exchange in the mid-latitudes with peak values of about 25 to $35 \times 10^{16} \mathrm{~kg} \mathrm{yr}^{-1}$ (with exact values depending on the definition of the tropopause and the method used to calculate the mass flux). As the stratosphere-troposphere air mass flux compares well to previous estimates, the too high values for the ozone mass flux are most likely due to anomalously high ozone mixing ratios in the stratosphere, that are known to occur in the model used here (Stenke et al., 2009).

As mass is conserved in the Lagrangian scheme, the mass fluxes to and from each box sum to zero (as rounded numbers are shown the sum of the numbers that are shown might differ slightly from zero). Ozone, on the other hand, has chemical sources and sinks and the net ozone mass flux for a region can therefore be different from zero (e.g. the tropical lower stratosphere shows a net flux out of the region). The integrated chemical production and destruction (and in the case of the troposphere, deposition) of ozone, whose sum equals the net transport, is indicated in each region.

The air mass fluxes clearly reflect the well-known circulation in the stratosphere, with net upwelling in the tropics, net poleward transport of air from low to higher latitudes and downwelling into the troposphere in the extratropics. The largest downward mass flux into the troposphere occurs in the mid-latitudes. In the tropical middle stratosphere the positive net air mass fluxes into the mid-latitudes are balanced by upward fluxes. The ozone mass fluxes show that in the tropical stratosphere more ozone is transported out of this region (into the extratropics) than into this region, as expected since the tropical stratosphere is a known source region for ozone. However, transport does not act in one direction only but a considerable exchange of air masses takes place through two-way mixing (Plumb, 2007). Here, the tracer flux in both directions across the defined boundaries can be explicitly quantified. The (ozone) mass fluxes into mid-latitudes of about $4 \times 10^{16} \mathrm{~kg} \mathrm{yr}^{-1}\left(35 \times 10^{10} \mathrm{~kg} \mathrm{yr}^{-1}\right)$ are partly balanced by fluxes into the tropics of roughly $2 \times 10^{16} \mathrm{~kg} \mathrm{yr}^{-1}$ $\left(25 \times 10^{10} \mathrm{~kg} \mathrm{yr}^{-1}\right)$. With the method used here, not only net ozone mass fluxes, but fluxes into and from each region to each other can be determined (the values are listed in Table 1).

The net flux of air mass and of ozone mass between two regions can be of different sign, depending on the ozone gradient in this region. For example the mass flux from the troposphere into the lower stratosphere in the tropics is positive (as expected from upwelling in this region), but the net ozone flux is downward. This can be easily understood as the ozone mixing ratios are much smaller in the troposphere than in the lower stratosphere. In the extratropics, the net fluxes from the stratosphere into the troposphere are downward both for mass and ozone mass, but while the upward ozone flux is close to zero, the upward mass fluxes are not negligible.

\section{Attribution of long-term ozone changes to chemistry and transport}

\subsection{Method}

The ozone budget equation (Eq. 1) partitions the ozone tendency into terms associated with transport and with chemistry. The chemistry and transport tendencies for different climate states can be compared, but do not necessarily explain the causes of the ozone changes as the ozone mixing ratio at one point is the result of the balance between the different sources and sinks. The attribution of differences in ozone mixing ratios between different climate states to changes in sources and sinks can be obtained as follows:

two different states of the atmosphere, for example two time periods ( $p_{1}$ and $\left.p_{2}\right)$ are compared under the assumption that ozone is approximately in balance within each period, i.e. there is no drift in the ozone mixing ratios over this period. For each period, the ozone budget equation for the annual mean change in ozone is:

$$
\begin{aligned}
& {\left[\frac{\partial \mathrm{O}_{3}}{\partial t}\right]^{p_{1}}=[P]^{p_{1}}-\left[D \mathrm{O}_{3}\right]^{p_{1}}+[T]^{p_{1}} \approx 0} \\
& {\left[\frac{\partial \mathrm{O}_{3}}{\partial t}\right]^{p_{2}}=[P]^{p_{2}}-\left[D \mathrm{O}_{3}\right]^{p_{2}}+[T]^{p_{2}} \approx 0}
\end{aligned}
$$

Here the integration denoted by $[\cdot]$ is the integral over the time periods $p_{1}$ and $p_{2}$, respectively. Assuming the ozone to be in balance requires the mean of the annual tendency in ozone over each time period to be zero. In practice, for the method to work, $\left[\frac{\partial \mathrm{O}_{3}}{\partial t}\right]^{p}$ has to be negligible compared to the other terms in the equation. For $\left[D \mathrm{O}_{3}\right] \approx[D]\left[\mathrm{O}_{3}\right]$, the equations above can be transformed to describe the relative change in ozone as: 


$$
\begin{aligned}
R_{\mathrm{O}_{3}} & =\frac{\left[\mathrm{O}_{3}\right]^{p_{2}}-\left[\mathrm{O}_{3}\right]^{p_{1}}}{\left[\mathrm{O}_{3}\right]^{p_{1}}} \\
& =\frac{[D]^{p_{1}}}{[D]^{p_{2}}}\left(\frac{[P]^{p_{2}}-[P]^{p_{1}}}{[P]^{p_{1}}+[T]^{p_{1}}}+\frac{[T]^{p_{2}}-[T]^{p_{1}}}{[P]^{p_{1}}+[T]^{p_{1}}}+1\right)-1
\end{aligned}
$$

It can be seen from this equation that if there were only changes in the destruction rate (i.e. $[P]^{p_{2}}=[P]^{p_{1}}$ and $[T]^{p_{2}}$ $\left.=[T]^{p_{1}}\right)$, the resulting changes in ozone are

$R_{\mathrm{O}_{3}}^{D}=[D]^{p_{1}} /[D]^{p_{2}}-1=\left([D]^{p_{1}}-[D]^{p_{2}}\right) /[D]^{p_{2}}$.

Similarly, changes solely in production cause changes in ozone of

$R_{\mathrm{O}_{3}}^{P}=\left([P]^{p_{2}}-[P]^{p_{1}}\right) /\left([P]^{p_{1}}+[T]^{p_{1}}\right)$

and changes solely in transport cause ozone changes of

$R_{\mathrm{O}_{3}}^{T}=\left([T]^{p_{2}}-[T]^{p_{1}}\right) /\left([P]^{p_{1}}+[T]^{p_{1}}\right)$.

Changes in the destruction rate are directly transferable to changes in ozone (i.e. a $10 \%$ reduction in the local destruction rate translates to $10 \%$ more ozone). Changes in production or transport, on the other hand, have to be considered relative to the total amount of a potential ozone "source", i.e. the sum of production and transport.

The relative change in ozone can then be written as:

$$
\begin{aligned}
R_{\mathrm{O}_{3}} & =\left(R_{\mathrm{O}_{3}}^{D}+1\right)\left(R_{\mathrm{O}_{3}}^{P}+R_{\mathrm{O}_{3}}^{T}+1\right)-1 \\
& =R_{\mathrm{O}_{3}}^{D}+R_{\mathrm{O}_{3}}^{P}+R_{\mathrm{O}_{3}}^{T}+R_{\mathrm{O}_{3}}^{D}\left(R_{\mathrm{O}_{3}}^{P}+R_{\mathrm{O}_{3}}^{T}\right)
\end{aligned}
$$

When relative changes are small $(\leq 0.1)$, the last term is an order of magnitude smaller than the first terms and can be neglected so that the total relative change in ozone is approximately equal to the sum of the relative changes due to destruction, production and transport changes:

$R_{\mathrm{O}_{3}} \approx R_{\mathrm{O}_{3}}^{D}+R_{\mathrm{O}_{3}}^{P}+R_{\mathrm{O}_{3}}^{T}$

The change in ozone due to transport can further be separated into transport of ozone from different regions by using the ozone origin diagnostic. As $[T]=\sum_{i=1}^{9}\left[T_{i}\right]$, the change in ozone due to transport equals $R_{\mathrm{O}_{3}}^{T}=\sum_{i=1}^{9}\left(\left[T_{i}\right]^{p_{2}}-\right.$ $\left.\left[T_{i}\right]^{p_{1}}\right) /\left([P]^{p_{1}}+[T]^{p_{1}}\right)$. This provides insight into whether changes in ozone are due to changes in export or due to changes in import, and for the latter, the region ozone is imported from. The uncertainty in each relative contributor is determined by calculating the joint standard deviation $\sigma=\sqrt{\left(\sigma_{1}^{2}+\sigma_{2}^{2}\right) / N}$, where $\sigma_{1}$ and $\sigma_{2}$ are the standard deviation of the annual mean values of $D, P$ and $T$ over periods $p_{1}$ and $p_{2}$ with length $N$.

\subsection{Results: attribution of long-term changes}

The relative difference of the mean ozone mixing ratio in each region was calculated between the decades 2040-2049 and 2000-2009 from the transient simulation. The relative changes in ozone due to changes in production, destruction and transport were calculated using Eq. (5). Figure 10 shows the results for each region with the transport term separated into changes due to import and export of ozone. The first two bars in each plot show the relative difference in ozone calculated directly from the ozone changes (middle term of Eq. 5) and from the right hand side of Eq. (5). If the assumption that ozone being in balance over the regarded periods (as made in Eq. 4) is valid, the two bars should be equal. Even though ozone is known to change rapidly during the periods regarded here, it can be seen that within the uncertainty bounds of the directly calculated difference, the two bars cannot be distinguished, i.e. the assumption is fulfilled sufficiently well. It is important to make this check before interpreting the following results, as they are only valid if this check shows that the method works for the region and periods considered.

The ozone mixing ratios increase from 2000 to the mid 21 st century in most regions of the atmosphere, only in the tropical lower stratosphere is the difference close to zero. The attribution method allows the changes in ozone to be attributed to chemical and dynamical processes. In the stratospheric regions, the changes in ozone are generally largely driven by changes in chemistry. A decrease in the destruction rates leads to higher ozone mixing ratios in the mid-latitudes, the tropical middle stratosphere and the polar regions. In the southern polar region, the largest relative difference in ozone in the stratosphere occurs (about 10\%). Reductions in destruction rates would lead to an increase in ozone mixing ratios of approximately $20 \%$. The increase is, however, counteracted by a negative effect on ozone due to less import of ozone into the southern polar stratosphere. The changes in the southern polar stratosphere are examined in more detail below. Another region in the stratosphere in which changes in transport play an important role is the tropical lower stratosphere. Even though the overall changes in ozone are close to zero here, it turns out that this is due to the cancellation of changes in transport and chemistry. While production increases, the overall change due to transport results in a reduction in ozone due to enhanced export of ozone. The finding that transport has a larger impact in the lower stratosphere compared to regions that include the middle stratosphere can be expected, as short life-times of ozone in the middle stratosphere compared to timescales of transport cause ozone mixing ratios to be chemically controlled there. In the lower stratosphere, where ozone life-times are longer, ozone mixing ratios are controlled by dynamics to a larger degree.

In the troposphere, ozone increases by about 10 to $20 \%$. This is largely due to an increase in production, counteracted by enhanced export. The increase in export can be understood as increased ozone mixing ratios leading to an increase 

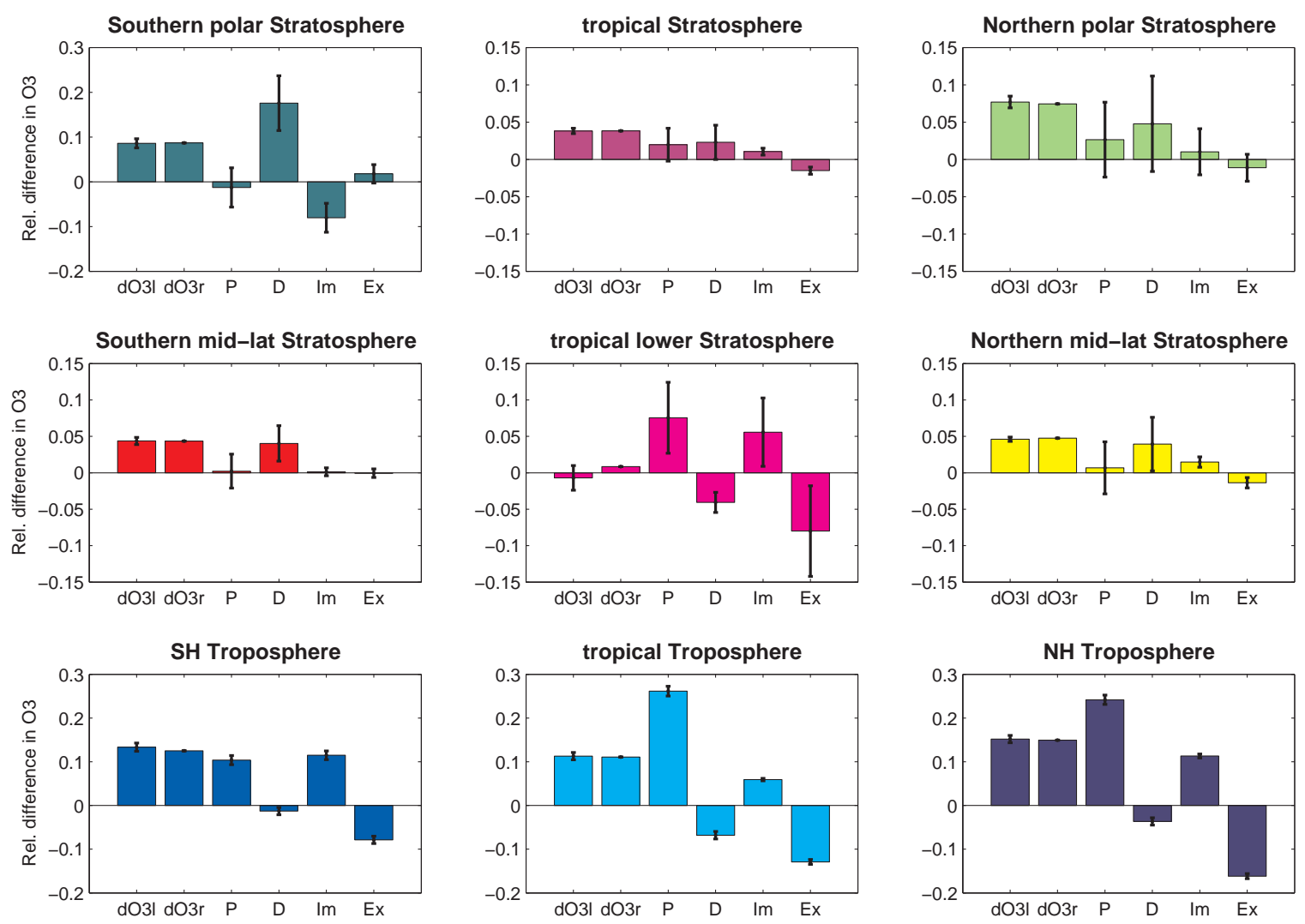

Fig. 10. Relative differences $2040 \mathrm{~s}-2000 \mathrm{~s}$ in mean ozone mixing ratios $\left(\left(\mathrm{O}_{3}^{p 2}-\mathrm{O}_{3}^{p 1}\right) / \mathrm{O}_{3}^{p 1}\right)$ of each region. The first bar and the second bar are the differences calculated from the left and right hand side of Eq. (5). The other bars are changes in ozone over this period due to changes in chemistry (production $[P]$ and destruction rates $[D]$ ) and dynamics (import, Im, and export, Ex). The errorbars denote the $1 \sigma$ uncertainty in the differences.

in export even if the air mass flux remains the same. In the Southern Hemisphere troposphere, enhanced import of ozone is the largest contributor to the positive trend.

Employing the ozone origin diagnostic allows separation into not only import and export, but also into the region ozone is imported from. In Fig. 11 the changes in ozone mixing ratios in the southern polar stratosphere are shown with the changes due to transport partitioned into the 9 ozone origin regions. As noted above, the strong increase in ozone due to decreased destruction rates is partly counteracted by decreased import of ozone. The partitioning reveals that the decrease in import is predominantly a decrease of ozone imported from the southern mid-latitudes (denoted as "smS" in Fig. 11). The export of ozone (i.e. transport of local ozone, "spS") also decreases slightly (not significant), implying less exchange of ozone between mid-latitudes and the polar region. The changes in ozone transport might be caused by either changes in the strength of the transport (i.e. of air mass fluxes) or by changes in the ozone mixing ratios. The decreased import of ozone from mid-latitudes could be explained by decreased mass transport or by decreased ozone mixing ratios in the mid-latitudes. As the latter is not the

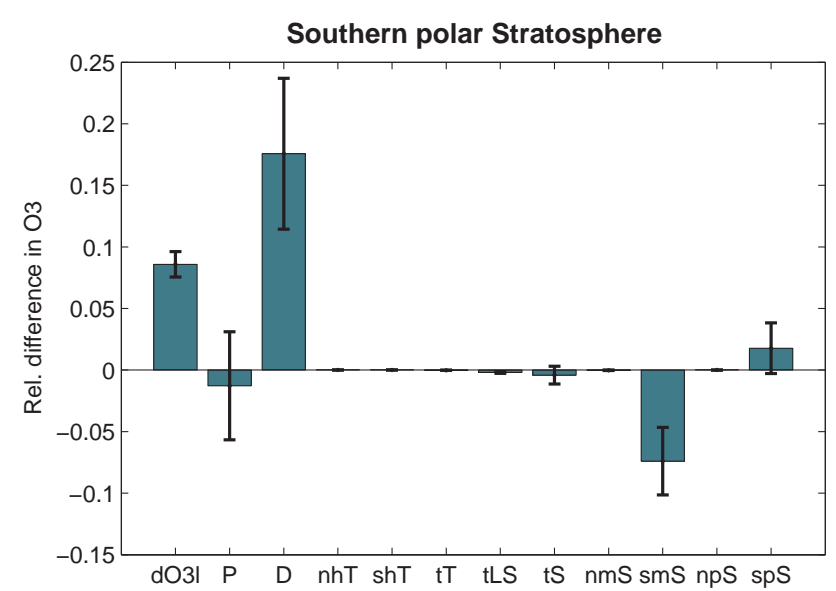

Fig. 11. As in Fig. 10 but for the southern polar stratosphere only and with the changes due to import split up into import from each region (the region labels correspond to those in Table 1).

case (ozone mixing ratios increase in mid-latitudes), it is likely that changes in the circulation cause the ozone transport change. 


\section{Summary and outlook}

A new method is demonstrated that allows a quantification of the impact of changes in transport on ozone changes in CCMs and CTMs. The ozone origin diagnostic is used here in combination with a decomposition of ozone tendencies, therefore not only allowing the determination of the origin of ozone but also of the ozone mass fluxes between different regions of the atmosphere. When comparing two climate states that are approximately in steady state, changes in ozone can be quantitatively attributed to changes in chemical production, destruction and transport.

To apply the ozone attribution method described here it is necessary to (1) implement the ozone origin diagnostic in the chemistry scheme of the model and (2) save the production and destruction rates of ozone as model output. Details on the implementation of the ozone origin diagnostic are given in Appendix B. The additional computational cost of the origin diagnostic is minimal; the only cost is the storage of the additional tracers.

Obviously the results shown here depend on the particular model used. To assess whether the findings presented here are valid generally, it will be necessary to apply the method to other model systems. To also capture the upper part of the ozone layer, models that fully include the middle and upper stratosphere are necessary. However, the results on the origin of ozone are comparable for models with a high or low top (Grewe, 2006).

The ozone attribution method presented is only one possible version, and there is scope for improvement and modifications. In this version, fixed geographical regions are used to divide the ozone field. It may be advantageous to divide the atmosphere according to dynamically separated regions, e.g. use the actual tropopause to divide the troposphere from the stratosphere instead of a fixed pressure level. This could be achieved by using the climatological values of the tropopause as the boundary between the pre-defined regions, which is probably a good approximation as the interannual variability of the tropopause height is small compared to the vertical model resolution. Furthermore, air masses inside and outside the polar vortex could be separated by using, for example, PV gradients to determine the polar barrier. However, when using time varying boundaries, the interpretation of the results requires acknowledging that the volume of the origin region changes with time, which also has an impact on the export and import of ozone. Another possibility is to further separate the chemical terms into production and destruction caused by different reaction cycles. This can be easily done as long as the production and destruction rates for the individual reaction cycles are saved as model output. It would also be desirable to be able to separate the effect of the available radiation for photodissociation. Even if the concentrations of all chemical species remain the same, changes in the amount of available photons by absorption at layers above the region of interest (i.e. non-local influence of ozone above a given layer) can change ozone production and destruction. This is so far not incorporated in the method, and will be a focus of future improvements.

The attribution method has a wide field of applications in model assessments. By applying the method to various CCMs, it will be possible to conduct process oriented comparison of these models. So far, only derived quantities are generally used to estimate the contribution of chemical or dynamical processes to these differences (e.g. Austin et al., 2010). When applying the ozone attribution method to different models (i.e. use two different models instead of different periods in the analysis presented in Sect. 4) it will be possible to track the differences in simulated ozone to differences in the amount of ozone produced, destroyed or transported. For the comparison of models either geographically fixed or dynamical boundaries can be used to define the regions, depending on the question asked (as discussed above). Dynamical boundaries allow for the comparison of cross-barrier transport, while fixed boundaries allow the direct comparison of ozone values and their sources and sinks in certain regions (in this case, the different dynamical states have to be taken into account to interpret the differences found). Unfortunately, it will obviously not be possible to apply the method directly to observational data. However there is the possibility to use chemistry-transport models that are based on observed wind fields, or even assimilated data sets such as that from Kiesewetter et al. (2010). A comparison of these data sets with CCMs using the ozone attribution method will allow an evaluation of the processes modelled by CCMs in a quantitative manner.

The attribution of ozone tendencies and changes on monthly, interannual and long-term timescales to chemistry and transport can help to reveal the various processes forcing changes in ozone. For example, it is known that the quasibiennial oscillation and the solar cycle impact ozone (e.g. Randel and Cobb, 1994; Bodeker et al., 2007; Dameris et al., 2006), and the processes are widely understood (e.g. Kinnersley and Tung, 1999; Gray and Pyle, 1989). However, using the new methodology introduced here, it will be possible to explicitly quantify the relative contribution to the anomalies induced by transport changes and by local chemistry.

\section{Appendix A}

\section{The E39C-A model and simulation description}

In this study, the CCM ECHAM4.L39(DLR)/CHEM/ATTILA (E39C-A) is used. The model is an updated version of ECHAM4.L39(DLR)/CHEM (E39C) (Hein et al., 2001; Dameris et al., 2005) with the former semi-Lagrangian advection scheme replaced by the fully Lagrangian advection scheme ATTILA (Reithmeier and Sausen, 2002). In ATTILA, the mass of the model atmosphere is divided into approximately 500000 air parcels of equal mass which are 
advected three-dimensionally using the actual model wind field. The use of the fully Lagrangian advection scheme ATTILA for tracer-transport improved the model performance substantially (Stenke et al., 2008, 2009). E39C is based on the spectral general circulation model ECHAM4.L39(DLR) (Land et al., 2002) and the chemistry-module CHEM (Steil et al., 1998). The spectral horizontal resolution of the model is $\mathrm{T} 30$, corresponding to approximately $3.75^{\circ} \times 3.75^{\circ}$ on the transformed latitude-longitude grid. In the vertical, the model consists of 39 layers, extending from the surface to the uppermost layer which is centred at $10 \mathrm{hPa}$. The chosen time step is $24 \mathrm{~min}$. The chemistry module CHEM is based on a generalised family concept and includes homogeneous and stratospheric heterogeneous ozone chemistry and the most relevant chemical processes for describing the tropospheric background chemistry. The current model version includes a parametrisation for the bromine chemistry. For more details on E39C-A, see Stenke et al. (2009).

The E39C-A simulation used in this study follows the definition of the SCN-B2d simulation given in Eyring et al. (2008). The simulation spans 1960 to 2049 following a $10 \mathrm{yr}$ spin-up. The ozone origin diagnostic was, however, only incorporated after 2000. The boundary conditions follow mostly observations in the past and projections in the future. The sea surface temperatures are taken from the HadGEM general circulation model (Johns et al., 2006). Concentrations of well-mixed greenhouse gases and anthropogenic $\mathrm{NO}_{\mathrm{x}}$ emissions, as well as ozone depleting substances, follow observations in the past and are prescribed according to the SRESA1B scenario (IPCC, 2001) and to the adjusted A1 scenario (WMO, 2007; Eyring et al., 2008), respectively, after 2000. The simulation includes natural variability, i.e. the solar cycle, the quasi-biennial oscillation and major volcanic eruptions in the past are considered. Details on the simulation can be found in Garny et al. (2009).

\section{Appendix B}

\section{Implementation of the ozone origin diagnostic}

The implementation of the ozone origin diagnostic is described here step by step. The additional ozone tracer fields are handled as any tracer in respect to the transport. The following operations are applied in the chemistry scheme of the model.

\section{Setup}

\subsection{Define $N$ regions}

At first, any desired number of regions of origin that subdivide the atmosphere need to be defined (i.e. the nine regions in the example shown here). Different ways to divide the atmosphere and their advantages and disadvantages are discussed in Sect. 2.
0.2. Implement and initialize $N$ additional ozone fields + two fields for production and destruction

For each defined region, an additional tracer field needs to the introduced. The fields can be arbitrarily initialized (as the method converges, i.e. for any initial condition the sum of the tracers will equal the full ozone field after enough integrations; see Sect. 2). However, it is recommended to initialize the tracers in a way that reduces the spin-up time; especially in regions with long chemical lifetimes initialized ozone concentrations will decay slowly. A good way of initializing is to assign to each ozone tracer field the concentrations of the full ozone field within the corresponding region, and set the concentrations to zero elsewhere. In addition, two output fields are needed to save the total ozone production and destruction (see below). The $N$ tracer fields are saved as output variables, desirable at daily resolution. To calculate the accumulated change in ozone over a certain period, the ozone fields at the first and last timestep of the period must be known (see Sect. 3). The total chemical production and destruction of ozone should be saved as means over the output intervals.

In the model integration, for each timestep and for each gridpoint $(\theta, \phi, z)$, the following operations are conducted:

1. Mass fixing of ozone tracer fields

Even though the sum of the nine tracer fields are mathematically equal to the full ozone field, numerical diffusion leads to discrepancies in the fields. Therefore, the $N$ additional ozone fields need to be scaled to the full ozone field by the scaling factor SF as follows:

$$
\begin{gathered}
\mathrm{SF}=\frac{\sum_{i=1}^{N} \mathrm{O}_{3}^{i}(\theta, \phi, z)}{\mathrm{O}_{3}(\theta, \phi, z)} \\
\mathrm{O}_{3}^{i}(\theta, \phi, z) \leftarrow \mathrm{O}_{3}^{i}(\theta, \phi, z) \times \mathrm{SF} \text { for } i=1 \ldots N
\end{gathered}
$$

The left arrow $(\leftarrow)$ indicates the assignment of fields $\mathrm{O}_{3}^{i}$ with the values on the right hand side (i.e. the rescaled ozone fields). The variables $\mathrm{O}_{3}^{i}$ and $\mathrm{O}_{3}$ are the additional $N$ ozone fields and the conventional ozone field in number density (molecules $\mathrm{cm}^{-3}$ ). The scale factor SF can be applied to the ozone fields in any unit (either mixing ratio or number density), but for the calculation of SF ozone needs to be in units of number density (or mass).

2. Determine total ozone production $P$ and total destruction rate $D$ 
Determine the total chemical production rate $P$ of ozone at the considered timestep at the current gridpoint, and $D$, the percentage rate of total chemical destruction of ozone (i.e. $D=$ ozone that is destroyed at a gridpoint per unit time/ozone at this gridpoint). These variables need to be saved as model output to apply the diagnostics described in Sect. 3 and Sect. 4.

\section{Add chemistry tendencies to each ozone tracer field}

The determined amounts of ozone production and destruction need to be added to each of the tracer fields according to Eq. (1), i.e. production is only added to the tracer associated with the region in which the current gridpoint lies, while destruction is applied to all fields according to their relative contribution. The production and destruction terms are applied to the $N$ ozone tracer fields in a way, that the sum of the production and destruction over the $N$ fields equals the production and destruction of the full ozone field.

\subsection{Destruction}

The total chemical destruction rate $D$ in units of $1 / \mathrm{s}$ is multiplied with the length of the timestep $\Delta t$ and is applied to each of the $N$ ozone fields in the same manner and each ozone field with destruction applied is assigned to the ozone fields:

$$
\begin{array}{r}
\mathrm{O}_{3}^{i}(\theta, \phi, z) \leftarrow \mathrm{O}_{3}^{i}(\theta, \phi, z) \times D \Delta t \\
\text { for each } i=1 \ldots N
\end{array}
$$

\subsection{Production}

The region $j$ in which the current gridpoint $(\theta, \phi, z)$ lies is determined. The total production $P$ (in units of ozone/time) at the current gridpoint is multiplied with the length of the timestep $\Delta t$ and is added to ozone field $j$ only (i.e. only to the ozone field that consists of ozone that is produced in region $j$ ). Therefore, only the ozone field $j$ is assigned with:

$$
\mathrm{O}_{3}^{j}(\theta, \phi, z) \leftarrow \mathrm{O}_{3}^{j}(\theta, \phi, z)+P \Delta t
$$

The ozone origin diagnostic is implemented in the CCM E39C-A used here. Furthermore, the ozone origin diagnostic is also implemented in the EMAC model (Jöckel et al., 2006) and will be released and as a module available in the next EMAC release.

Acknowledgements. The authors want to thank Dan Smale for helpful discussions and comments. Thanks also to Patrick Jöckel, Birgit Hassler and the two anonymous reviewer for comments on the manuscript. This study was funded by the Deutsche Forschungsgemeinschaft (DFG) through the DFG-research group SHARP (Stratospheric Change And its Role for climate Prediction).

Edited by: O. Boucher

\section{References}

Austin, J., Scinocca, J., Plummer, D., Oman, L., Waugh, D., Akiyoshi, H., Bekki, S., Braesicke, P., Butchart, N., Chipperfield, M., Cugnet, D., Dameris, M., Dhomse, S., Eyring, V., Frith, S., Garcia, R., Garny, H., Gettelman, A., Hardiman, S. C., Kinnison, D., Lamarque, J., Mancini, E., Marchand, M., Michou, M., Morgenstern, O., Nakamura, T., Pawson, S., Pitari, G., Pyle, J., Rozanov, E., Shepherd, T., Shibata, K., Stolarski, R., Teyssedre, H., Wilson, R., and Yamashita, Y.: The decline and recovery of total column ozone using a multi-model time series analysis, J. Geophys. Res., 115, D00M10, doi:10.1029/2010JD013857, 2010.

Bodeker, G. E., Garny, H., Smale, D., Dameris, M., and Deckert, R.: The 1985 Southern Hemisphere mid-latitude total column ozone anomaly, Atmos. Chem. Phys., 7, 5625-5637, doi:10.5194/acp7-5625-2007, 2007.

Dameris, M., Grewe, V., Ponater, M., Deckert, R., Eyring, V., Mager, F., Matthes, S., Schnadt, C., Stenke, A., Steil, B., Brühl, C., and Giorgetta, M. A.: Long-term changes and variability in a transient simulation with a chemistry-climate model employing realistic forcing, Atmos. Chem. Phys., 5, 2121-2145, doi:10.5194/acp-5-2121-2005, 2005.

Dameris, M., Matthes, S., Deckert, R., Grewe, V., and Ponater, M.: Solar cycle effect delays onset of ozone recovery, Geophys. Res. Lett., 33, L03806, doi:10.1029/2005GL024741, 2006.

Eyring, V., Chipperfield, M., Giorgetta, M., Kinnison, D. E., Manzini, E., Matthes, K., Newman, P., Pawson, S., Shepherd, T., and Waugh, D.: Overview of the New CCMVal Reference and Sensitivity Simulations in Support of Upcoming Ozone and Climate Assessments and Planned SPARC CCMVal, SPARC Newsletter, 30, 20-26, 2008.

Eyring, V., Cionni, I., Bodeker, G. E., Charlton-Perez, A. J., Kinnison, D. E., Scinocca, J. F., Waugh, D. W., Akiyoshi, H., Bekki, S., Chipperfield, M. P., Dameris, M., Dhomse, S., Frith, S. M., Garny, H., Gettelman, A., Kubin, A., Langematz, U., Mancini, E., Marchand, M., Nakamura, T., Oman, L. D., Pawson, S., Pitari, G., Plummer, D. A., Rozanov, E., Shepherd, T. G., Shibata, K., Tian, W., Braesicke, P., Hardiman, S. C., Lamarque, J. F., Morgenstern, O., Pyle, J. A., Smale, D., and Yamashita, Y.: Multi-model assessment of stratospheric ozone return dates and ozone recovery in CCMVal-2 models, Atmos. Chem. Phys., 10, 9451-9472, doi:10.5194/acp-10-9451-2010, 2010.

Eyring, V., Cionni, I., Lamarque, J. F., Akiyoshi, H., Bodeker, G. E., Charlton-Perez, A. J., Frith, S. M., Gettelman, A., Kinnison, D. E., Nakamura, T., Oman, L. D., Pawson, S., and Yamashita, Y.: Sensitivity of 21st century stratospheric ozone to greenhouse gas scenarios, Geophys. Res. Lett., 37, 16807, doi:10.1029/2010GL044443, 2010.

Garny, H., Dameris, M., and Stenke, A.: Impact of prescribed SSTs on climatologies and long-term trends in CCM simulations, Atmos. Chem. Phys., 9, 6017-6031, doi:10.5194/acp-9-6017-2009, 2009.

Gettelman, A., Holton, J. R., and Rosenlof, K. H.: Mass fluxes of $\mathrm{O}_{3}, \mathrm{CH}_{4}, \mathrm{~N}_{2} \mathrm{O}$ and $\mathrm{CF} 2 \mathrm{Cl} 2$ in the lower stratosphere calculated from observational data, J. Geophys. Res., 102(D15), 1914919160, 1997.

Gray, L. and Pyle, J.: A two-dimensional model of the quasibiennial oscillation of ozone, J. Atmos. Sci., 46, 203-220, 1989.

Grewe, V.: The origin of ozone, Atmos. Chem. Phys., 6, 1495- 
1511, doi:10.5194/acp-6-1495-2006, 2006.

Grewe, V. and Dameris, M.: Calculating the global mass exchange between stratosphere and troposphere, Ann. Geophys., 14, 431442, doi:10.1007/s00585-996-0431-x, 1996.

Hein, R., Dameris, M., Schnadt, C., Land, C., Grewe, V., Köhler, I., Ponater, M., Sausen, R., B. Steil, B., Landgraf, J., and Brühl, C.: Results of an interactively coupled atmospheric chemistry general circulation model: Comparison with observations, Ann. Geophys., 19, 435-457, doi:10.5194/angeo-19-435-2001, 2001.

IPCC: Climate Change 2001 - The scientific basis, Tech. rep., Intergovernmental Panel on Climate Change, Cambridge University Press, New York, USA, 2001.

Jöckel, P., Tost, H., Pozzer, A., Brühl, C., Buchholz, J., Ganzeveld, L., Hoor, P., Kerkweg, A., Lawrence, M. G., Sander, R., Steil, B., Stiller, G., Tanarhte, M., Taraborrelli, D., van Aardenne, J., and Lelieveld, J.: The atmospheric chemistry general circulation model ECHAM5/MESSy1: consistent simulation of ozone from the surface to the mesosphere, Atmos. Chem. Phys., 6, 50675104, doi:10.5194/acp-6-5067-2006, 2006.

Johns, T. C., Durman, C. F., Banks, H. T., Roberts, M. J., McLaren, A. J., Ridley, J. K., Senior, C. A., Williams, K. D., Jones, A., Rickard, G. J., Cusack, S., Ingram, W. J., Crucifix, M., Sexton, D. M. H., Joshi, M. M., Dong, B.-W., Spencer, H., Hill, R. S. R., Gregory, J. M., Keen, A. B., Pardaens, A. K., Lowe, J. A., BodasSalcedo, A., Stark, S., and Searl, Y.: The New Hadley Centre Climate Model (HadGEM1): Evaluation of Coupled Simulations, J. Clim., 19, 1327-1353, 2006.

Kiesewetter, G., Sinnhuber, B.-M., Vountas, M., Weber, M., and Burrows, J. P.: A long-term stratospheric ozone data set from assimilation of satellite observations: Highlatitude ozone anomalies, J. Geophys. Res., 115, D10307, doi:10.1029/2009JD013362, 2010.

Kinnersley, J. and Tung, K.: Mechanisms for the extratropical QBO in circulation and ozone, J. Atmos. Sci., 56, 1942-1962, 1999.

Land, C., Feichter, J., and Sausen, R.: Impact of vertical resolution on the transport of passive tracers in the ECHAM4 model, Tellus B, 54, 344-360, 2002.

Oman, L. D., Plummer, D., Waugh, D., Austin, J., Scinocca, J., Douglass, A., Salawitch, R., Canty, T., Akiyoshi, H., Bekki, S., Braesicke, P., Butchart, N., Chipperfield, M., Cugnet, D., Dhomse, S., Eyring, V., Frith, S., Hardiman, S., Kinnison, D., Lamarque, J., Mancini, E., Marchand, M., Michou, M., Morgenstern, O., Nakamura, T., Nielsen, J., Olivie, D., Pitari, G., Pyle, J., Rozanov, E., Shepherd, T., Shibata, K., Stolarski, R., Teyssedre, H., Tian, W., and Yamashita, Y.: Multi-model assessment of the factors driving stratospheric ozone evolution over the 21st Century, J. Geophys. Res., 115, D24306, doi:10.1029/2010JD014362, 2010.
Plumb, R.: Tracer interrelationships in the stratosphere, Rev. Geophys., 45, RG4005, doi:10.1029/2005RG000179, 2007.

Portmann, R. W. and Solomon, S.: Indirect radiative forcing of the ozone layer during the 21st century, Geophys. Res. Lett., 34, L02813, doi:10.1029/2006GL028252, 2007.

Randel, W. and Cobb, J.: Coherent variations of monthly mean total ozone and lower stratospheric temperature, J. Geophys. Res., 99(D3), 5433-5447, 1994.

Randel, W., Gille, J., Roche, A., Kumer, J., Mergenthaler, J., Waters, J., Fishbein, E., and Lahoz, W.: Stratospheric transport from the tropics to middle latitudes by planetary-wave mixing, Nature, 365, 533-535, 1993.

Reithmeier, C. and Sausen, R.: ATTILA: atmospheric tracer transport in a Lagrangian model, Tellus B, 54, 278-299, 2002.

Steil, B., Dameris, M., Brhl, C., Crutzen, P. J., Grewe, V., Ponater, M., and Sausen, R.: Development of a chemistry module for GCMs: first results of a multiannual integration, Ann. Geophys., 16, 205-228, doi:10.1007/s00585-998-0205-8, 1998.

Stenke, A., Grewe, V., and Ponater, M.: Lagrangian transport of water vapour and cloud water in the ECHAM4 GCM and its impact on the cold bias, Clim. Dyn., 31, 491-506, 2008.

Stenke, A., Dameris, M., Grewe, V., and Garny, H.: Implications of Lagrangian transport for simulations with a coupled chemistry-climate model, Atmos. Chem. Phys., 9, 5489-5504, doi:10.5194/acp-9-5489-2009, 2009.

Stevenson, D. S., Dentener, F. J., Schultz, M. G., Ellingsen, K., van Noije, T. P. C., Wild, O., Zeng, G., Amann, M., Atherton, C. S., Bell, N., Bergmann, D. J., Bey, I., Butler, T., Cofala, J., Collins, W. J., Derwent, R. G., Doherty, R. M., Drevet, J., Eskes, H. J., Fiore, A. M., Gauss, M., Hauglustaine, D. A., Horowitz, L. W., Isaksen, I. S. A., Krol, M. C., Lamarque, J., Lawrence, M. G., Montanaro, V., Müller, J., Pitari, G., Prather, M. J., Pyle, J. A., Rast, S., Rodriguez, J. M., Sanderson, M. G., Savage, N. H., Shindell, D. T., Strahan, S. E., Sudo, K., and Szopa, S.: Multimodel ensemble simulations of present-day and near-future tropospheric ozone, J. Geophys. Res., 111, D08301, doi:10.1029/2005JD006338, 2006.

WMO: Scientific Assessment of Ozone Depletion: 2006, Tech. rep., WMO Global Ozone Research and Monitoring Project Report No. 50, Geneva, Switzerland, 2007.

WMO: Scientific Assessment of Ozone Depletion: 2010, Tech. rep., WMO Global Ozone Research and Monitoring Project Report, in press, 2010. 